\title{
A Practical Guide to a Safe Sequence of Donning and Doffing of Personal Protective Equipment in Relation to COVID-19
}

\author{
Vijay Samuel Richard ${ }^{1}$ Muralidhar Kanchi \\ ${ }^{1}$ Consultant, Hospital Infection Control \\ ${ }^{2}$ Department of Cardiac Anaesthesia and Critical Care, Narayana \\ Institute of Cardiac Sciences, Bangalore, Karnataka, India
}

\begin{abstract}
Address for correspondence Muralidhar Kanchi, MD, FIACTA, FICA, MBA, FASE, Department of Anaesthesia and Critical Care, Narayana Institute of Cardiac Sciences, Narayana Health City, \#258/A, Bommasandra Industrial Area, Anekal Taluk, Bangalore 560099 , Karnataka, India (e-mail: muralidhar.kanchi.dr@narayanahealth.org).
\end{abstract}

\begin{abstract}
When caring for patients with suspected or confirmed COVID-19 (coronavirus disease 2019), especially when involved in procedures that generate aerosol, personal protective equipment (PPE) with full-body coverage is recommended. The Centers for Disease Control and Prevention emphasizes and recommends the following principles with regard to donning and doffing of PPE: (1) training and education (rigorous

Keywords

- doffing

- donning

$-P P E$

- COVID-19 and repeated training of the health care workers [HCWs]), (2) all HCWs must exhibit competency in the PPE donning and doffing, and (3) PPE doffing should be done in a manner that prevents self-contamination or self-inoculation with contaminated PPE or hands (remove the most contaminated PPE items first, perform hand hygiene at each stage of doffing, and discard disposable items in containers for biomedical waste).
\end{abstract}

\section{General Principles}

When caring for patients with suspected or confirmed COVID-19 (coronavirus disease 2019), especially when involved in procedures that generate aerosol, personal protective equipment (PPE) with full-body coverage is recommended. The Centers for Disease Control and Prevention emphasizes and recommends the following principles with regard to donning and doffing of PPE: (1) training and education (rigorous and repeated training of the health care workers [HCWs]), (2) all HCWs must exhibit competency in the PPE donning and doffing, and (3) PPE doffing should be done in a manner that prevents self-contamination or self-inoculation with contaminated PPE or hands (remove the most contaminated PPE items first, perform hand hygiene at each stage of doffing, and discard disposable items in containers for biomedical waste).

\section{Procedure for Donning the PPE}

The procedure for donning the PPE is as follows: (1) wear the PPE in a designated area before entering the patient care area, (2) undertake the procedure of putting on PPE under the guidance and supervision of a trained observer (colleague), (3) remove all personal items such as watch, jewelry, pen, cell phone, and so on, (4) use the restroom and drink sufficient water before starting to wear the PPE, (5) before donning, ensure that all required PPE are available, and (6) follow the steps as shown in $\boldsymbol{- F i g . ~} \mathbf{1}$.
DOI https://doi.org/

10.1055/s-0040-1712804

ISSN 2457-0206.
(O2020 Official Publication of The Simulation Society (TSS), accredited by International Society of Cardiovascular Ultrasound (ISCU).
License terms

()(1) $\Theta \circledast$ 


\section{DONNING OF PERSONAL PROTECTIVE EQUIPMENT (PPE)}

\section{Precautions before DONNING the PPE}

- Wear the PPE in a designated area before entering the patient care area

- Undertake the procedure of putting on PPE under the guidance \& supervision of a trained observer (colleague)

- Remove all personal items like the watch, jewellery, pen, cell phone, etc...

- Please use the restroom \& drink sufficient water before starting to wear the PPE

- Before donning, ensure all the required PPEs are available
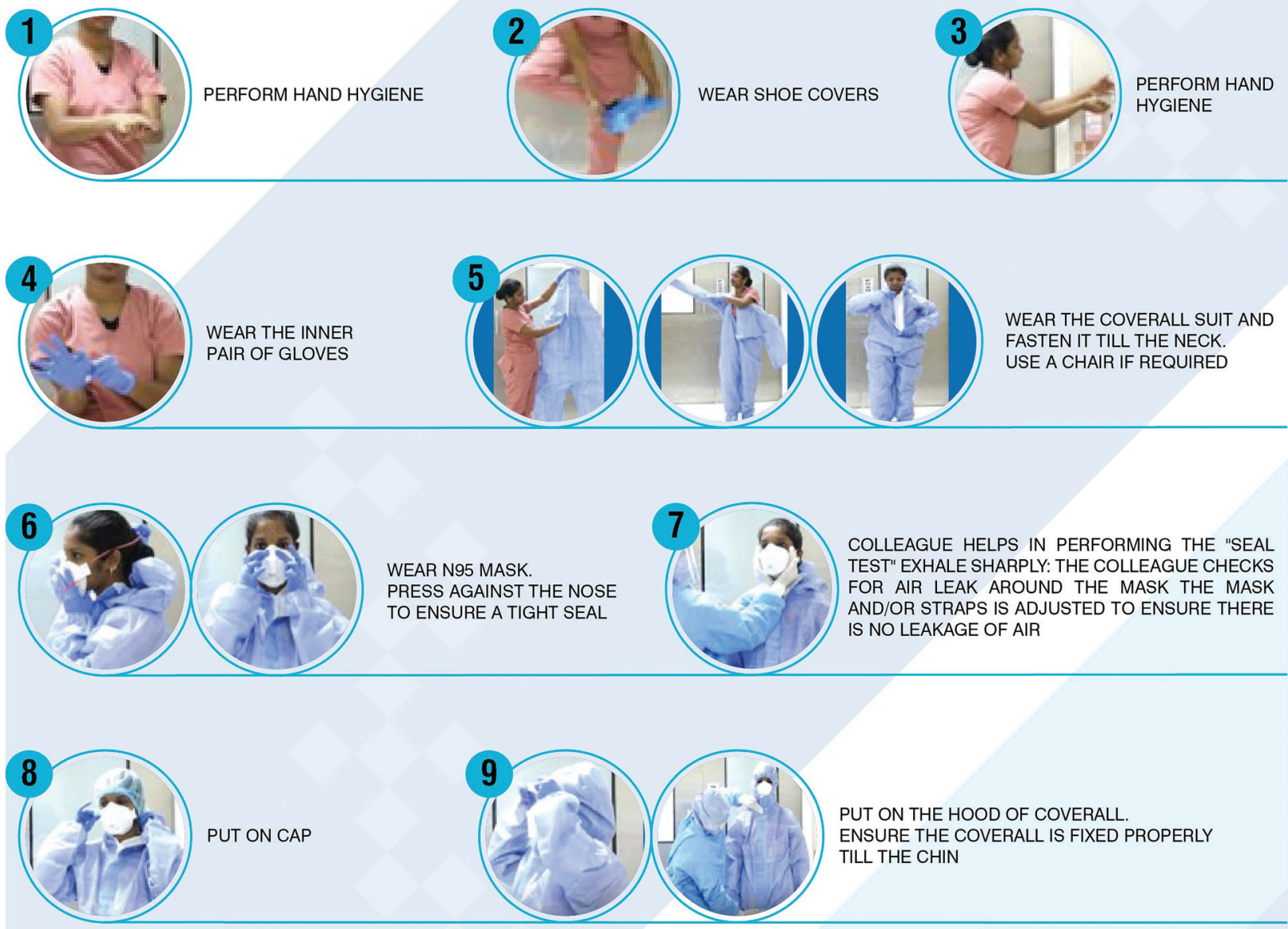

PUT ON THE HOOD OF COVERALL.

ENSURE THE COVERALL IS FIXED PROPERLY

TILL THE CHIN
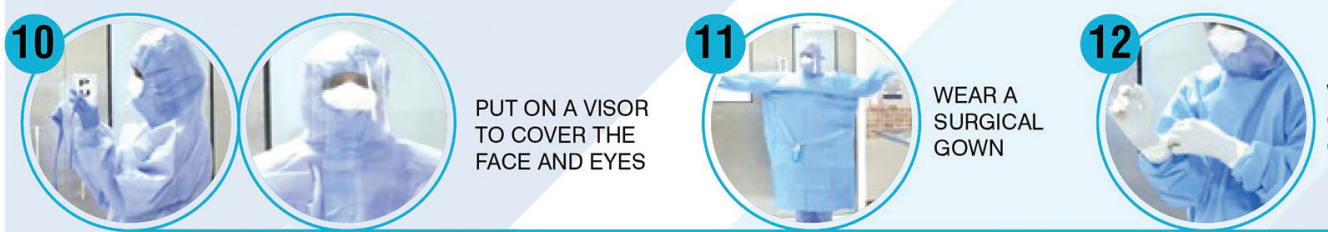

WEAR A SECOND PAIR OF GLOVES OVER THE CUFF OF THE GOWN

THE COLLEAGUE (OBSERVER) WILL PERFORM A FINAL CHECK BEFORE THE PERSON ENTERS THE PATIENT CARE AREA.

Fig. 1 Donning of personal protective equipment (PPE). 


\section{DOFFING OF PERSONAL PROTECTIVE EQUIPMENT (PPE)}

Precautions before DOFFING of PPE

- Doffing is done in a designated area

- Always perform doffing under the guidance and supervision of a trained observer or colleague

- Ensure PPE is discarded immediately into the appropriate bin
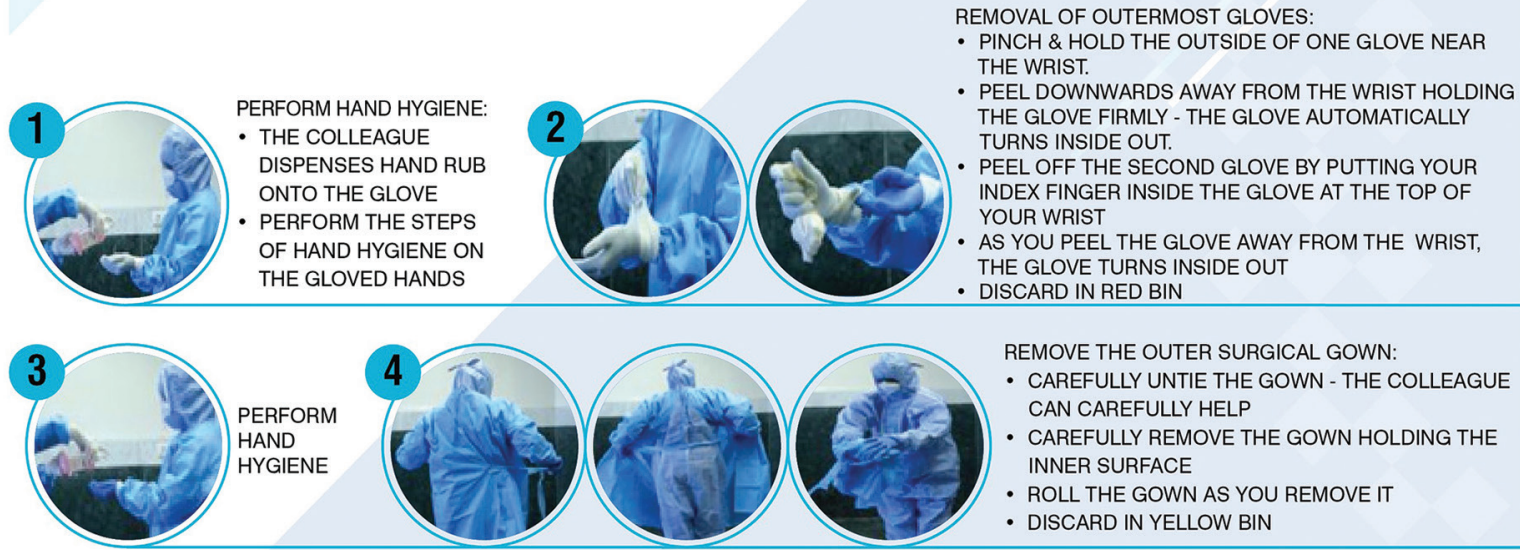

REMOVE THE OUTER SURGICAL GOWN:

- CAREFULLY UNTIE THE GOWN - THE COLLEAGUE CAN CAREFULLY HELP

- CAREFULLY REMOVE THE GOWN HOLDING THE INNER SURFACE

- ROLL THE GOWN AS YOU REMOVE IT

- DISCARD IN YELLOW BIN
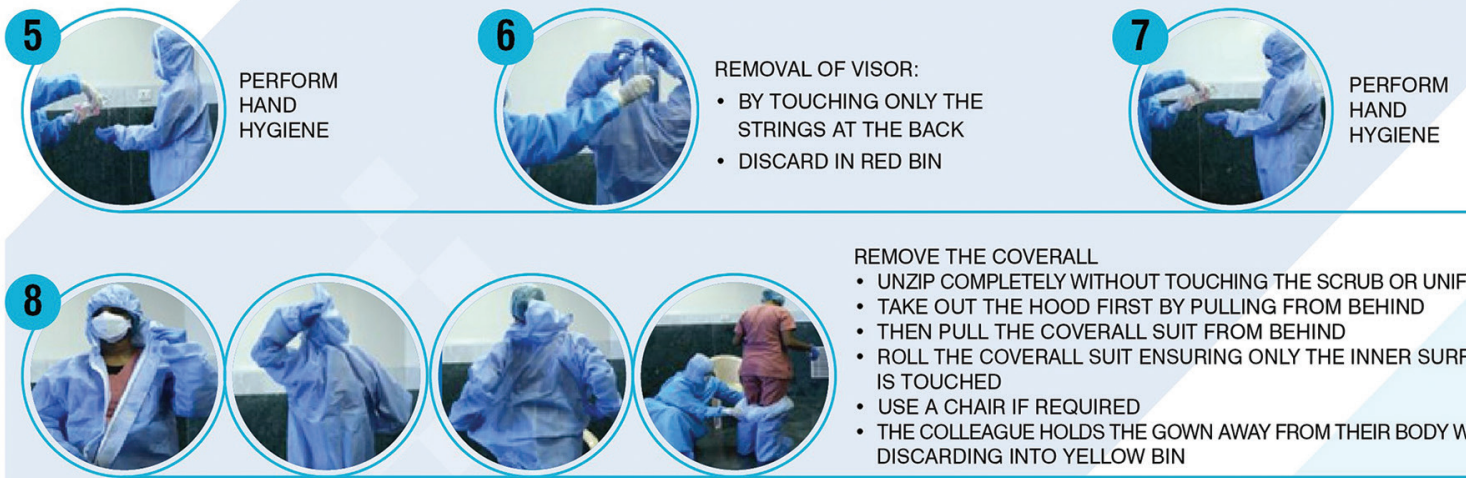

REMOVE THE COVERALL

- UNZIP COMPLETELY WITHOUT TOUCHING THE SCRUB OR UNIFORM

- TAKE OUT THE HOOD FIRST BY PULLING FROM BEHIND

- THEN PULL THE COVERALL SUIT FROM BEHIND

- ROLL THE COVERALL SUIT ENSURING ONLY THE INNER SURFACE IS TOUCHED

- USE A CHAIR IF REQUIRED

- THE COLLEAGUE HOLDS THE GOWN AWAY FROM THEIR BODY WHILE DISCARDING INTO YELLOW BIN
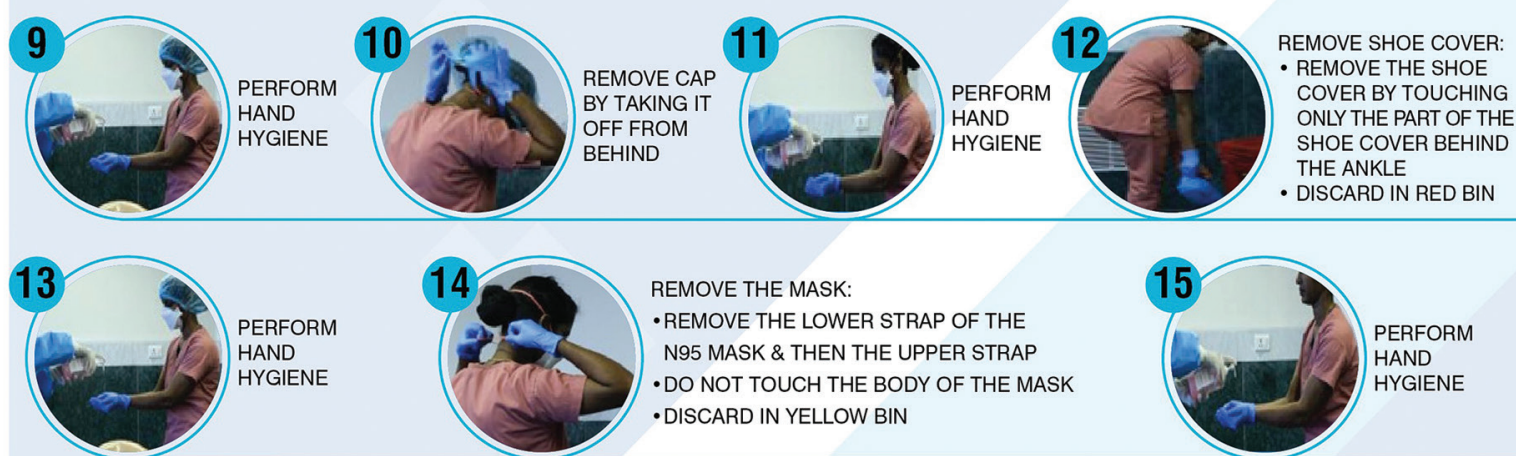

REMOVE THE MASK

- REMOVE THE LOWER STRAP OF THE N95 MASK \& THEN THE UPPER STRAP -DO NOT TOUCH THE BODY OF THE MASK - DISCARD IN YELLOW BIN
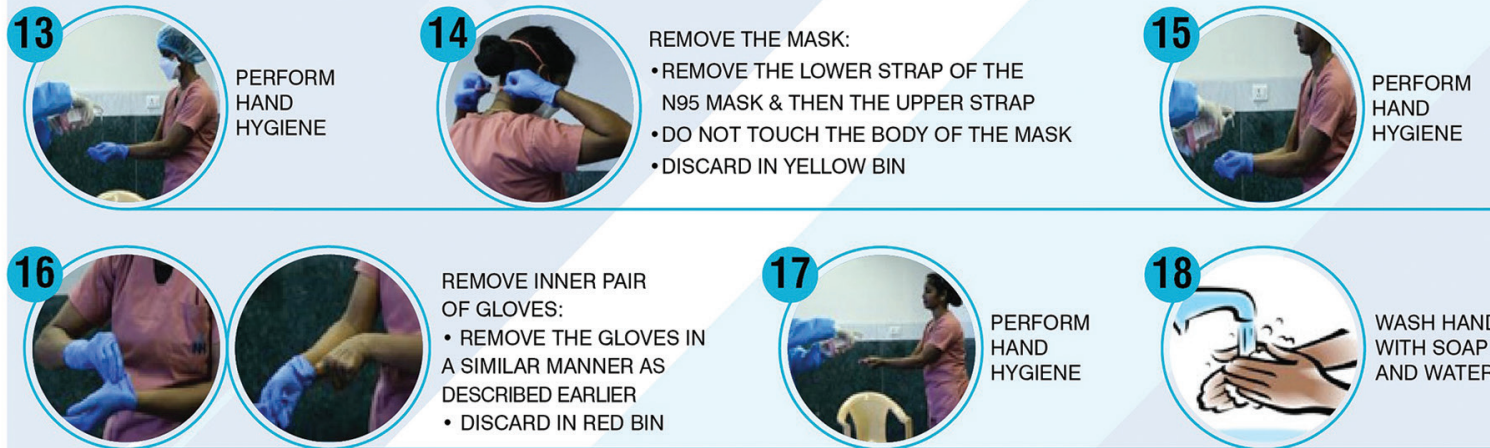

Fig. 2 Doffing of personal protective equipment (PPE).

\section{Procedure for Doffing of PPE}

The procedure for doffing of PPE is as follows: (1) doffing is done in a designated area, (2) always perform doffing under the guidance and supervision of a trained observer or colleague, and
(3) ensure that PPE is discarded immediately into the appropriate bin, and (4) follow the steps shown in $\boldsymbol{- F i g .} \mathbf{2}$.

\section{Conflict of Interest}

None. 